\title{
Dealing with Academic Dishonesty
}

\author{
S. Geethalakshmi
}

Vice-Chancellor, The Tamil Nadu Dr. M.G.R. Medical University, Chennai-32

Corresponding Author: S. Geethalakshmi

E-mail: vc@tnmgrmu.ac.in

\begin{abstract}
The University has the responsibility to ensure academic integrity among its faculty and student community. Academic dishonesty is a misconduct that includes cheating, plagiarism, falsification and fabrication of any information, multiple submissions, violation of ethical and professional standards in academic programs and courses. The consequences of academic dishonesty can influence personal, professional, ethical and legal spheres. The students and faculty are responsible for complying with all University regulations and requirements of the respective Councils. Disciplinary action may be imposed on any student or faculty for violation of University rules and regulations. Some of the main causes for academic dishonesty are peer pressure, performance anxiety, excuse making, inability to manage the demands of student life, situations that encourage academic dishonesty, self-justification habits, unfamiliarity with what constitutes academic dishonesty and lack of understanding about consequences. The consequences of academic dishonesty are the penalties that the university can impose on the offending student or the faculty. Other consequences include social consequences, loss of intellectual property, inaccurate assessment, practical concerns, legal consequences, other social/academic consequences and diminishing self-esteem of students. Ethical principles and practices in the profession and the punishments and action imposed in academic dishonesty should be imparted to faculty and students. Group Assignments, research papers and writing assignments can be prepared regarding clearly defined citation expectations, describing plagiarism and paraphrasing, creating benchmarks and critical thinking. Therefore, preserving the academic integrity and preventing the growth of academic dishonesty is a pivotal part of Quality Assurance in the education system of the University.
\end{abstract}

Key words: academic dishonesty, medical colleges, academic integrity, students, university

\section{INTRODUCTION}

Every University has the responsibility to ensure academic integrity among its faculty and student community. Academic dishonesty is a misconduct that includes cheating, plagiarism, falsification and fabrication of any information, multiple submissions, violation of ethical and professional standards in academic programs and courses [1]. It also includes bribery, sabotage, deception, and impersonation. Scholars note that cheating was prevalent on the Chinese civil service exams thousands of years ago, even when cheating carried the penalty of death for both examinee and examiner [2]. Bribing the examiners was also common at that time and these have been recorded in the Ming-dynasty and Qing-dynasty story collections. 
In this manuscript, selected studies are compared on the basis of my experience.

Good medical professional in addition to knowledge and skills must be equipped with high ethical and moral standards [3]; thus, increasing the quality of healthcare. The medical students are the cream of the society and are not expected to cheat in class tests or examinations. But the intense pressure to pass the examinations makes some of the students to be dishonest. Previous studies have reported academic dishonesty in the medical field. Cheating is prevalent in Croatian medical schools and academic dishonesty is seen as acceptable behaviour among numerous future Croatian doctors [4]. In Iran, the most frequently reported type of academic dis-integrity was found to be 'impersonating an absent student in a class' (93\%) and the least frequent to be 'legitimising absences by using bribes' (5\%). Only a small number of interns considered 'buying hospital shifts', 'selling hospital shifts', 'impersonating an absent student' and 'helping others to cheat in examinations' as representing academic disintegrity [5]. In another study from South India, 75\% have given proxy for attendance and $49 \%$ have copied from others record book. During a theory exam, $74 \%$ of medical students have copied from their friends, $2 \%$ have tried to get the question paper before exam and $5 \%$ have influenced their teachers by unfair means to get more marks. During clinical/practical exam, $81 \%$ have got technical help, $45 \%$ had prior knowledge about the exam case, and $54 \%$ of them have falsely documented clinical findings [6]. Technological tools are also available for the students and faculty to facilitate plagiarism, falsification, fabrication of data, which gives rise to more challenges to the University. Thus, moral standards that are placed on each professional has two main obligations: the responsibility of developing his or her personal standards and the required self-discipline to practice in accordance with these standards [7].

\section{Types of Academic Dishonesty}

Medical field is ever growing, expanding and progressing day by day. Medical knowledge is available in literature in vast numbers of journals, books and World Wide Web. Plagiarism is nothing but adoption or reproduction of ideas or data of another person in your work and statements of another person without due acknowledgment. A review article published in 2017 described medical students plagiarising work of seniors and peers, self-plagiarism and plagiarizing from other sources without acknowledging the reference [8]. Academic plagiarism is on the rise in India also. Increasing pressure to publish, deficient training in ethical scientific writing, ignorance, oversight and lack of statutory controls and clear policies to deal with scientific misconduct in academics has led to the rise of research misconduct which can severely impact growth of India's higher education system [9]. Therefore, The Tamil Nadu Dr. MGR Medical University has introduced the plagiarism detection software which provides the percentage of copied contents that are taken from other research papers. All the postgraduate dissertations, Ph.D Thesis are analysed using the software. As the students and faculty are aware of this implementation, there is a decrease in plagiarism in the University.

Fabrication of data is inventing imaginary data to satisfy the required results and outcome. In Netherlands, a study conducted among 315 scientists concluded that $15 \%$ of the scientists admitted they had fabricated, falsified, plagiarized, or manipulated data in the past 3 years. And the scientific misconduct was more common among younger scientists working in a university hospital [10]. The Tamil Nadu Dr. MGR Medical University tackles fabricating data by reviewing the research work of students stringently. Review committees are set up to frequently evaluate the progress of the research projects. Deception is providing false information to the teacher/instructor concerning a formal academic exercise. One of the common examples is giving false excuse for missing a deadline. The student laments that somebody at home has fallen very sick. Some of them provide false claims of submitting the work and that it is lost. Teachers need to have contact with students and learn to deal with them.

Cheating is an attempt to give or obtain assistance in a formal academic exercise (like in examination) without due acknowledgment. Most of us would have seen it in examination process. In my experience as a medical teacher for more than three decades and as an administrator, I have seen students falsely asking for scribe in the pretext of having fracture of the 
fingers or wrist. I refer to the medical board and surprisingly the medical board given their statement with no fracture at all and seem fit to write the examination. I have also noticed the students used rubbers to share answers for MCQs, used ear phones. For this purpose, my University had strictly instructed affiliated institutions to ban mobile phones in the examination halls and install CCTV Cameras and mobile jammers.

Students often resort to provide money for assignments and test answers. This very often happens in the engineering field. Some commercial centres advertise to complete the projects for students for money. This is rare in the medical field but it does happen. However, some students may attempt to sabotage other students work. They try and cut pages from the library books or attempt to wilfully disrupt other student's experiments. On rare occasions, students may take effort to impersonate another student; assuming a student's identity to provide an advantage for the student. To prevent this, the University releases hall tickets for examinations with photos and encourages CCTV cameras in the examination halls.

\section{Causes of Academic Dishonesty}

Most of the students attempt dishonest behaviour due to peer pressure. They try to achieve high marks or perform the assignments at a faster pace. Some students are anxious to perform well and therefore resort to dishonest ways. Sometimes they observe other students cheating and join them. However, the most common reason is that the students are unable to cope with the pressures of their social and academic lives. A study of pharmacy and medical students in New Zealand found that students' actions (honest or dishonest) were guided by family and friends, the need to do well, issues of morality and institutional guidelines [11]. A study among nursing students in South Africa reported the pressure to succeed academically was a major factor influencing the decision to engage in cheating behavior [12]. And medical students in Ethiopia reported that lack of preparation for exams, academic workload or other assignments, need to obtain good marks and desire not to fail exams were the major cause of academic dishonesty [13]. Occasionally students may complain that their professors expect too much or are too difficult to understand. Rarely if any questions are asked in the examinations out of syllabus, students tend to cheat.

There are some situations that encourage academic dishonesty. When the course regulations do not spell out clearly the consequences and penalties of violating the academic integrity standards and when the medical teachers and instructors are not careful in enforcing academic integrity standards. In some centres the teachers encourage dishonesty to get good name. Therefore, teachers have to be careful as the students look up to them and copy them. Like anti-ragging, students must be made aware that they will be suspended or removed from the institution if they practice academic dishonesty. Also, when they copy and cheat in examinations, they should be aware that they will be debarred for three months or years or consecutive sessions as per the norms of the University.

\section{Consequences}

There are many consequences of academic dishonesty. The most obvious consequences of academic dishonesty are the penalties that the university can impose on the offending student or the faculty. Once dishonest behaviour becomes a habit, it will be harmful to the society as well as to the person itself. For e.g. students who cheat, may continue to do so at work, in family life and other aspects of life. The patient does not need such doctors who are dishonest and unethical. A legal case can be filed against them. Other consequences are loss of intellectual property, [14] inaccurate assessment, practical concerns, other social/academic consequences and diminishing self-esteem of students [15]. Students with low self esteem may have difficulty in their careers and families. Therefore, all students must be taught bioethics. 


\section{Dealing with Academic Dishonesty}

Establishing a culture of integrity starts at the University level and can filter down to the individual medical teachers of the medical colleges. The medical faculty must become familiar with institution's policies, regulations and practices. They also need to notify students of the policies and regulations wherever a marks or grades are involved, syllabi, assignments and project sheets, statement of expected behaviour, etc. They should develop in-class exercises to help students with proper methods of citation, encourage them to attend research methodology workshops and provide classes on how to write a paper. They should design tests and assignments to minimize opportunities to engage in dishonest behaviour. For example, negative markings, Multiple Choice Questions (MCQs) and online tests. Establish clear rules on the use of electronic devices in class. If permissible, deal with isolated instances on an informal in-class basis but be sure to observe all class and institutional procedures are maintained. Once a culture of integrity has been embraced at the institutional level, it can be instilled in individual students, faculty, and administrators [16].

The University approach for the administrators involves review institution's policies regulations and practices: look for comprehensive statements on dealing with instances of academic misconduct. Make sure the policies and regulations are in line with Central Councils and the institution's mission, policies, customs, and/or existing honor code and that they are being followed meticulously. Make sure that faculty and students can find the policies and academic decisions (website, handbooks, orientation). Publications of an online Frequently Asked Questions guide to issues of Academic Dishonesty so that students and faculty can access reliable information anytime [17]. Review syllabi/curricula, if necessary, compose a short statement or web page URL that can be inserted into a syllabus. Create opportunities for faculty, administrators, and student leaders to talk about academic dishonesty frequency of instances, effective responses, due process, etc. Periodically review the process for compliance and practicality. We have to teach other teachers and other students about what is dishonesty, regulations, rules, policies and what are the punishments involved. Further, penalties should be given consistently through a fair evaluation process since mixed messages regarding penalties for academic misconduct may in fact encourage students to engage in academic misconduct [18].

\section{CONCLUSIONS}

The University needs to take initiative for its faculty to become familiar with curriculum, policies, regulations and practices. The students should be notified of the policies and regulations wherever marks/grade is involved: syllabi, assignment and project sheets, statement of expected behaviour. The colleges need to remind students of expectations just before starting a test or assignment. The faculty can further design tests and assignments to minimize opportunities to engage in dishonest behaviour. Group Assignments, research papers and writing assignments can be prepared regarding clearly defined citation expectations, describing plagiarism and paraphrasing, creating benchmarks and critical thinking. Clear rules need to be established on the use of electronic devices in class. If permissible, deal with isolated instances on an informal in-class basis but be sure to observe all class and institutional procedures. It is therefore critical that the University make concerted effort to include bioethics into the curricula and establish sound academic integrity policies. Thus, preserving the academic integrity and preventing the growth of academic dishonesty is a pivotal part of Quality Assurance in the education system of the University.

\section{REFERENCES}

1. Defining Academic Integrity Misconduct: https://www.indstate.edu/code-of-studentconduct/academic-policies/defining-misconduct

2. Academic dishonesty: https://en.wikipedia.org/wiki/Academic_dishonesty 
3. Hafeez K, Khan MLZ, Jawaid M, Haroon S. Academic misconduct among students in medical colleges of Karachi, Pakistan. Pak J Med Sci 2013;29(3):699-702.

4. Taradi SK, Taradi M, Dogas Z. Croatian medical students see academic dishonesty as an acceptable behaviour: a cross-sectional multicampus study. J Med Ethics 2012;38(6):376-9.

5. Hejri SM, Zendehdel K, Asghari F, Fotouhi A, Rashidian A. Academic disintegrity among medical students: a randomized response technique study. Med Educ 2013;47(2):144-53.

6. Babu TA, Joseph NM, Sharmila V. Academic dishonesty among undergraduates from Private medical schools in India. Are we on the right track? Med Teach 2011;33(9):759-61.

7. Marques DN, Macedo AF. Perceptions of acceptable conducts by university students. J Optom 2016;9(3):166-74.

8. Mak-van der Vossen M van Mook W van der Burgt S, Kors J Ket, JCF, Croiset G. et al. Descriptors for unprofessional behaviours of medical students: a systematic review and categorization. BMC Med Educ 2017;17:164.

9. Juyal D, Thawani V, Thaledi S. Rise of academic plagiarism in India: Reasons, solutions and resolution. Lung India 2015;32(5):542-3.

10. Tijdink JK, Verbeke R, Smulders YM. Publication pressure and scientific misconduct in Medical Scientists. J Empir Res Hum Res Ethics 2014;9(5):64-71.

11. Henning MA, Ram S, Malpas P, Sisley R, Thompson A, Hawken SJ. Reasons for academic honesty and dishonesty with solutions: a study of pharmacy and medical students in New Zealand. J Med Ethics 2013;40(20):702-9.

12. Theart, C.J. \& Smit, I. The status of academic integrity amongst nursing students at a nursing education institution in the Western Cape. Curationis 2012;35(1):27.

13. Desalegn AA, Berhan A. Cheating on examinations and its predictors among undergraduate students at Hawassa University College of Medicine and Health Science, Hawassa, Ethiopia. BMC Med Educ 2014;14:89.

14. Tucci V, Galwankar S. JETS policy on plagiarism and academic dishonesty. J Emerg Trauma Shock 2011;4(1):3-6.

15. Korn L, Davidovitch N. The Profile of Academic Offenders: Features of Students Who Admit to Academic Dishonesty. Medical Science Monitor: Med Sci Monit 2016;22:3043-55.

16. Kusnoor AV, Falik R. Cheating in Medical School: The Unacknowledged Ailment. South Med J 2013;106(8):479-83.

17. Seals M, Hammons JO, Mamiseish K. Teaching Assistants' Preparation for, Attitudes Towards, and Experiences with Academic Dishonesty: Lessons Learned. International Journal of Teaching and Learning in Higher Education 2014;26(1):26-36.

18. Lee YJ, Noh JH, Choi HS, Kim SE. Nursing Students' Awareness and Behaviour of Academic Misconduct in South Korea. Indian J Sci Technol 2017;10(20):1-6.

Acknowledgements - Nil

Source of Funding - Nil

Conflict of Interest - Nil 